\title{
Antibiogram studies and extended spectrum beta-lactamase activity profile of Salmonella-like species isolated from poultry soil of the University of Uyo, Nigeria
}

\author{
Matthew Egbobor Eja ${ }^{1}$, Nsikan Samuel Udoekong ${ }^{2}$, Emmanuel Maundy Ikpeme $^{1}$, Kingsley Hovana Enyi-Idoh ${ }^{1 *}$, \\ Josiah Asime Lennox ${ }^{3}$, Kimboline Donatus Etim ${ }^{4}$. \\ ${ }^{1}$ Department of Biological Sciences, Cross River University of Technology, Calabar, Cross River State, Nigeria. \\ ${ }^{2}$ Department of Microbiology, University of Uyo, Akwa Ibom State, Nigeria. \\ ${ }^{3}$ Department of Microbiology, University of Calabar, Calabar, Cross River State, Nigeria. \\ ${ }^{4}$ Department of Public Health, College of Medical Sciences, University of Calabar, Calabar, Cross River State, Nigeria. \\ E.mail: kingenyi@gmail.com
}

Received $4^{\text {th }}$ May 2012; Received in revised form $2^{\text {nd }}$ July 2012; Accepted $3^{\text {rd }}$ July 2012

\begin{abstract}
Aims: The contribution of beta-lactamase activity of various bacterial species to the increased antimicrobial resistance being experienced worldwide is very scanty in the literature. This study was undertaken to investigate the antibiotic resistance pattern (antibiogram) of Salmonella-like bacterial species against some antibiotics, and the role betalactamase assumably produced by the Salmonella-like species, played in producing resistance.

Methodology and Result: The antimicrobial sensitivity test and the beta-lactamase test of the Salmonella-like species were carried out using the methods of Kirby Bauer sensitivity test and the Double Disk Synergy test respectively, following isolation and identification of the organisms from poultry soil. Results revealed that Salmonella-like species were most highly resistant to Nalidixic acid $(20,66.66 \%)$, followed by Tetracycline (19, 63.33\%), Cotrimoxazole, Amoxicillin and Augmentin (18,60\%), while the least was Ofloxacin (8, 26.66\%). Multiple resistance of 4 or more antibiotics among the isolates from the soil outside the broilers enclosure was observed, while there was a significant difference $(P<0.05)$ between poultry soil and control soil. This implied that the antibiotics with the highest resistance were most often applied to the birds, the droppings of which contaminated the soil. The resistant pattern of the isolates from the control soil is lower than that from the poultry soil. Extended Spectrum Beta-lactamase activity was expressed by all the isolates against Cefotazime, while the least resistance was against mostly Cefotazime.

Conclusion, significance and impact of study: It is concluded that there is a widespread Beta-lactamase activity causing antibiotic resistance by many species of bacteria as well as poultry Salmonella, thus exacerbating the global problem of antibiotic resistance and a serious health related implication for antibiotic use in poultry.
\end{abstract}

Keywords: Extended spectrum beta-lactamase, Salmonella-like species poultry soil, antibiogram, prevalence

\section{INTRODUCTION}

Bacteria are ubiquitous and inextricably linked to the lives of the organisms and larger environments they inhabit. Bacteria have short generation time and can respond rapidly to changes in their environment. Thus, as antimicrobial agents were introduced into the environment, bacteria responded by becoming resistant to these agents.

Rapid spread of genes of resistance to antimicrobial agents can occur in a bacterial population and from one ecosystem to another; hence the development of resistance in one bacterial population can spread to other populations overtime through sharing and exchange of resistance genes. In a variety of interconnected ecosystems, antimicrobial agents can lead to the emergence of resistance, the reduction of microorganisms susceptible to the agents, and the drastic alterations in the biodiversity of affected ecosystems.
Antimicrobial resistance is clinically relevant because 3 $10 \%$ of infections can progress to life-threatening bacteraemia, particularly in young and immunocompromised patients (Okeke et al., 2005). In Indonesia, Salmonella paratyphi recovered between 1995 and 2001 were universally susceptible to commonly used antimicrobials, while $S$. enteritidis were resistant to most of the antimicrobials tested, with the exception of flouroquinolones (Okeke et al., 2005). One of the studies in Spain reported high percentages of resistance of Salmonella isolates to sulfadiazine, neomycin, tetracycline and streptomycin, which might be the result of use of antibiotics as a prophylaxis or treatment (Carraminana et al., 2004). In Ethiopia, a resistance pattern of Salmonella isolates from chickens indicated large proportions of strains resistant to a variety of drugs (Molla et al., 2003), and this has led to a shift in the antibiotics used against Salmonella species in Nepal from chloramphenicol and ampicillin to trimethoprim-sulfamethoxazole, fluoroquinolones and ceftriaxone (Pokharel et al., 2006). 
The mechanisms of antimicrobial resistance are numerous including possession of additional gene by some bacteria for protection against bactericidal effects of drugs, change of their permeability to the drug in use, etc. One of the most disturbing mechanisms of resistance to drug is the production of an enzyme known as betalactamase by some bacteria. The beta-lactamase is responsible for the resistance of the bacteria to betalactam antibiotics like penicillin, cephamycins and carbapenems. These antibiotics have a common element in their molecular structure, and that is, a four-atom ring known as beta-lactum. The lactamase enzyme breaks the ring open, deactivating the molecule's antibacterial properties (Philippon et al., 2002).

This study, therefore, aims to examine the antibiotic resistance patterns and the beta-lactamase activity of Salmonella-like organisms isolated from the outside soil enclosure of the University of Uyo poultry farm. The isolates are described as Salmonella-like because they have not passed through Kauffmann-white serological identification.

\section{MATERIALS AND METHODS}

\section{Collection of soil samples}

Soil samples (top soil $5 \mathrm{~cm}$ deep) from the surroundings of broilers and layers houses of the University of Uyo Poultry Farm, Uyo, were collected from four different points at a distance of one meter apart. Soil samples from about $30 \mathrm{~m}$ to $50 \mathrm{~m}$ from the poultry houses were collected from ten different points and used as control. The samples were carried in polythene bags in ice-packed coolers to the microbiology laboratory of the University of Uyo, for analysis within 2-3 hours.

\section{Bacteriological Analysis}

Isolation procedure: Soil samples (25 g) were transferred with a sterile spatula into an Erlenmeyer flask. Buffered peptone water $(225 \mathrm{~mL})$ was added to the sample to obtain 1 part sample and 9 parts buffer. This was mixed and incubated at room temperature for $16-20$ h. The broth $(1 \mathrm{~mL})$ was transferred with a sterile pipette to $10 \mathrm{~mL}$ Tetrathionate Broth and incubated at room temperature. A loop full $\left(10 \mu^{-1}\right)$ was spread on Xylose Lysine Deoxyclolate (XLD) agar and Brilliant Green (BG) agar and incubated at room temperature for $18-24 \mathrm{~h}$. The incubated plates were examined for microbial growth.

A typical transparent zone of reddish colour with a black centre was seen on XLD agar, and the colonies on BG agar plate were grey-reddish/pink and slightly convex. These were repeatedly sub-cultured on nutrient agar to obtain pure colonies. All the pure cultures of Salmonellalike species were preserved on nutrient agar slopes in screw-capped bottles at $4{ }^{\circ} \mathrm{C}$.

\section{Identification of Suspect Salmonella}

From the pure culture, the suspected Salmonella was identified using the method of Cheesbrough (1991). This involves using a straight wire to tough the surface of an individual smooth colony, and stabbing into a tube of motility indole urea (MIU) medium and incubated at about $37{ }^{\circ} \mathrm{C}$ for up to $4 \mathrm{~h}$. This was examined at half hourly intervals. A pink colouring urease production was negative for Salmonella. Indole test was also carried out by placing an indole strip in the neck of the MIU inoculated tube, and reincubated at about $37^{\circ} \mathrm{C}$ overnight.

Then using a sterile straight wire, a tube of Kligler iron agar (KIA) was inoculated with a smooth colony from the XLD plate, stabbing first the butt, and then streaking the slope. This was closed with a loose-fitting cap and incubated at $37^{\circ} \mathrm{C}$ overnight. After overnight incubation, the MIU and KIA cultures were examined for reasons suggestive of Salmonella or Shigella. Salmonellae and Shigellae produced a pink-red slope and yellow butt indicating the fermentation of glucose but not lactose. However, S. paratyphi A, B and C crack in the medium due to gas production from glucose fermentation, while they produced $\mathrm{H}_{2} \mathrm{~S}$ except Salmonella paratyphi A. $S$. typhi produced only a small amount of blackening and no cracks in the medium. S. typhimurium gave unconfirmed gas production, thus, $S$. typhimurium was confirmed by culturing the suspect Salmonella on XLD and incubating at $37{ }^{\circ} \mathrm{C}$ overnight. Red-pink black centred colonies confirmed S. typhimurium.

\section{Antibiotic Sensitivity Test}

Multi-antibiotics disc (Oxoid, U.K.) with the following antibiotics was used. Cotrimoxazole $(125 \mu \mathrm{g})$, Amoxicillin $(25 \mu \mathrm{g})$, Tetracycline $(30 \mu \mathrm{g})$, Aumentin $(30 \mu \mathrm{g})$, Ofloxacin $(30 \mu \mathrm{g})$, Nalidixic acid $(30 \mu \mathrm{g})$, Gentamicin $(10 \mu \mathrm{g})$, and Nitrofurantoin $(30 \mu \mathrm{g})$.

The method used for the antimicrobial testing was the Kirby-Bauer disk diffusion method (Bauer et al., 1966) which has been reported to be one of the most commonly used antimicrobial susceptibility testing (Jorgensen et al., 1998).

Four to five culture colonies were selected from each plate and transferred into $0.9 \%$ saline to obtain turbidity equivalent to 0.5 McFarland barium sulphate standards.

The Mueller-Hinton agar plates were inoculated directly from the suspension, spreading the inoculum as evenly as possible with a sterile swab. Antimicrobial test discs were then placed aseptically using sterile forceps, on the inoculated medium. The plates were incubated inverted at $37^{\circ} \mathrm{C}$ for $18-24 \mathrm{~h}$, and the diameters of the zones of inhibition surrounding the discs were measured in millimeters. Multiple antibiotic resistance, which is the resistance to four or more antibiotics (Philips, 1991), was also determined. 
According to Cheesbrough (2002), the cut-off points used to discriminate between susceptible, intermediate and resistant strains were Gentamicin $10 \mu \mathrm{g}: \geq 15 \mathrm{~mm}$ for susceptible, $13-14 \mathrm{~mm}$ for intermediate and $\leq 12 \mathrm{~mm}$ for resistant strains. Catrimoxazole $25 \mu \mathrm{g}$ : $\geq 16 \mathrm{~mm}$ for susceptible, $11-15 \mathrm{~mm}$ for intermediate and $\leq 10 \mathrm{~mm}$ for resistant strains. Tetracycline $30 \mu \mathrm{g}: \geq 19 \mathrm{~mm}$ for susceptible, $15-18 \mathrm{~mm}$ for intermediate and $\leq 14 \mathrm{~mm}$ for resistant strains. Nitrofurantoin $30 \mu \mathrm{g}$ : $\geq 17 \mathrm{~mm}$ for susceptible, $15-16 \mathrm{~mm}$ for intermediate and $\leq 14 \mathrm{~mm}$ for resistant strains. Natidixic acid $30 \mu \mathrm{g}: \geq 19 \mathrm{~mm}$ for susceptible, $14-18 \mathrm{~mm}$ for intermediate and $\leq 13 \mathrm{~mm}$ for resistant strains.

\section{Extended-Spectrum Beta-Lactamase Test}

The presence of extended-spectrum beta-lactamase (ESBL) was presumptively detected by the Double Disk Synergy Test (DDT) (Livermore, 2001). This involved inoculating a suspension of test organism on Mueller Hinton agar. This was followed by placing a disk containing $30 \mu \mathrm{g}$ Amoxicillin plus Clavulanic acid centrally on the plate. Disks containing Ceftazidime and Cefotaxime were placed round the Amoxicillin plus Clavulanic acid disk at a distance of $20 \mathrm{~mm}$ (centre to centre) from the latter. The plates were incubated overnight at $35{ }^{\circ} \mathrm{C}$. The patterns of zones of inhibition were noted. Isolates that exhibited a distinct shape/size with a tendency towards Amoxicillin plus Clavulanic acid disk were considered Extended-spectrum Beta-lactamase producers.

The extended-spectrum beta-lactamase was detected by cefotazime showing the highest resistance by all the isolates, and ceftazidime showing the least resistance by all the isolates.

\section{Statistical Analysis}

Differences, if any, in the resistance patterns (Antibiogram) of the various isolates from the soil samples, were determined using t-test statistical method (Bailey, 1981; Miller and Miller, 1986).

\section{RESULTS}

The biochemical differentiation of Salmonella-like isolates is represented in Table 1. The isolates were differentiated into Salmonella paratyphi A, S. paratyphi C, S. typhimurium and S. typhi D.

The prevalence of Salmonella-like isolates from poultry soil showing resistance is represented in Table 2. Salmonella-like isolates were most resistant to Nalidixic acid $20(66.66 \%)$, followed by Tetracycline $19(63.33 \%)$, Cotrimoxazole, Amoxicillin and Augmentin 18(60\%), while the least was ofloxacin $8(26.66 \%)$. The isolates from control soil showed resistance $3(30 \%)$ for Gentamicin and $1(10 \%)$ for cotrimoxazole, Augmentin and Nitrofurantoin. Similarly, isolates from the soil outside the broiler enclosure revealed a higher multiple resistance pattern of
Table 1: Biochemical differentiation of Salmonella-like isolates

\begin{tabular}{|c|c|c|c|c|c|c|c|}
\hline \multirow[t]{2}{*}{$\begin{array}{l}\text { Probable } \\
\text { Isolates }\end{array}$} & 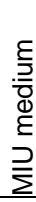 & & & 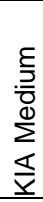 & & & \\
\hline & 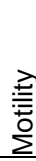 & $\begin{array}{l}\frac{0}{0} \\
\frac{0}{0}\end{array}$ & 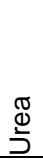 & $\frac{0}{\infty}$ & $\begin{array}{l}\text { F } \\
\text { D }\end{array}$ & $\begin{array}{l}\widehat{D} \\
\text { I } \\
\text { I } \\
\frac{\tilde{D}}{\tilde{m}}\end{array}$ & 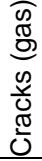 \\
\hline S. paratyphi A & + & - & - & $\mathrm{R}$ & $\bar{Y}$ & - & + \\
\hline S. paratyphi C & + & - & - & $\mathrm{R}$ & $\mathrm{Y}$ & + & + \\
\hline S. typhimurium & + & - & - & $\mathrm{R}$ & $\mathrm{Y}$ & + & u \\
\hline S. typhi D & + & - & - & $\mathrm{R}$ & $Y$ & $\begin{array}{l}+ \\
\text { weak }\end{array}$ & - \\
\hline
\end{tabular}

$\mathrm{u}=$ unconfirmed gas production; MIU = motility indole urea; $\mathrm{KIA}=$ Kligler iron agar; $\mathrm{R}=$ red; $\mathrm{Y}=$ yellow .

Table 2: Prevalence of Salmonella-like species showing resistance in poultry soil samples

\begin{tabular}{|c|c|c|}
\hline \multirow[t]{2}{*}{ Antibiotics } & \multicolumn{2}{|c|}{$\begin{array}{l}\text { Number (\%) of Salmonella-like } \\
\text { species showing resistance }\end{array}$} \\
\hline & $\begin{array}{l}\text { Poultry soil }^{2} \\
(n=30)\end{array}$ & $\begin{array}{l}\text { Control soil }^{a} \\
(\mathrm{n}=10)\end{array}$ \\
\hline Cotrimoxazole $25 \mu \mathrm{g}$ & $18(60)$ & $1(10)$ \\
\hline Amoxicillin & $18(60)$ & $0(0)$ \\
\hline Tetracycline $30 \mu \mathrm{g}$ & $19(63.33)$ & $2(20)$ \\
\hline Augmentin & $18(60)$ & $1(10)$ \\
\hline Ofloxacin & $8(26.66)$ & $2(20)$ \\
\hline Nalidixic Acid $30 \mu \mathrm{g}$ & $20(66.66)$ & $2(20)$ \\
\hline Gentamicin $10 \mu \mathrm{g}$ & $13(43.33)$ & $3(30)$ \\
\hline Nitrofurantoin $30 \mu \mathrm{g}$ & $17(56.66)$ & $1(10)$ \\
\hline
\end{tabular}

$\mathrm{n}=$ number of samples

${ }^{\text {a }} P<0.05$, poultry soil vs. control soil

4 or more antibiotics than those from the soil around the layers enclosure and control (Table 3). Results of soil samples were compared using the student t-test, and they revealed that there was a significant difference $(P<0.05)$ in the resistance pattern of isolates from soil outside the poultry enclosures and control.

Table 3: Resistance Patterns of Salmonella-like species showing resistance in poultry soil samples

\begin{tabular}{llll}
\hline Resistance to & \multicolumn{2}{l}{$\begin{array}{l}\text { Number } \\
\text { species showing resistance }\end{array}$} \\
\cline { 2 - 4 } & $\begin{array}{l}\text { Broiler soil } \\
(\mathrm{n}=20)\end{array}$ & $\begin{array}{l}\text { Layer soil } \\
(\mathrm{n}=30)\end{array}$ & $\begin{array}{l}\text { Control } \\
(\mathrm{n}=10)\end{array}$ \\
\hline 6 or more Antibiotics & $7(35)$ & $1(10)$ & $0(0.00)^{\mathrm{b}}$ \\
4 or more Antibiotics & $16(80)$ & $5(50)$ & $0(0.00)^{\mathrm{b}}$ \\
2 or more Antibiotics & $20(100)$ & $10(100)$ & $2(20)^{\mathrm{b}}$ \\
No Antibiotics & $0(0.00)$ & $0(0.00)$ & $1(10)$ \\
\hline
\end{tabular}

$\mathrm{n}=$ number of samples

${ }^{\mathrm{b}} P<0.05$, poultry soil vs. control soil

Table 4 shows the results of the extended spectrum betalactamase activity of the Salmonella-like isolates. The extended spectrum beta-lactamase activity was detected by cefotazime showing the highest resistance by all the isolates, and ceftazidime showing the least resistance by all the isolates. 
Table 4: Extended Spectrum Beta-lactamase Activity of Salmonella-like isolates of soil samples

\begin{tabular}{llll}
\hline Isolates & \multicolumn{3}{c}{ Antibiotics } \\
\cline { 2 - 4 } & $\begin{array}{l}\text { AUG } \\
(30 \mu \mathrm{g})\end{array}$ & $\begin{array}{l}\text { CEFO } \\
(30 \mu \mathrm{g})\end{array}$ & $\begin{array}{l}\text { CAZ } \\
(30 \mu \mathrm{g})\end{array}$ \\
\hline S. paratyphi A & $6 \mathrm{~mm}$ & $6 \mathrm{~mm}$ & $10 \mathrm{~mm}$ \\
S. paratyphi C & $6 \mathrm{~mm}$ & $8 \mathrm{~mm}$ & $13 \mathrm{~mm}$ \\
S. typhimurium & $6 \mathrm{~mm}$ & $8 \mathrm{~mm}$ & $12 \mathrm{~mm}$ \\
S. typhi $D$ & $9 \mathrm{~mm}$ & $10 \mathrm{~mm}$ & $13 \mathrm{~mm}$ \\
\hline
\end{tabular}

$\mathrm{AUG}=$ Amoxicillin and Clavulanic (Resistance $<13 \mathrm{~mm}$ )

CEFO = Cefotazime (Resistance $<14 \mathrm{~mm}$ )

$\mathrm{CAZ}=$ Ceftazidime $($ Resistance $<14)$.

\section{DISCUSSION}

Varying reactions were observed in the use of antimicrobials against the Salmonella-like isolates from poultry soil. The isolates showed moderate resistance to Ofloxacin $(26.66 \%)$ with the highest resistance to Nalidixic acid $(66.66 \%)$. The isolates from control soil showed the highest resistance (30\%) to Gentamicin followed by Cotrimoxazole, Augmentin and Nitrofurantoin (10\%). Even then, isolates from poultry soil showed greater resistance $(43.33 \%)$ to Gentamicin. This was interpreted to mean that isolates from outside soil of poultry house were more resistant to antibiotics than those of the control which might have been contaminated through run-off water from the poultry farm (Arikpo et al., 2006). Of course, there is a significant difference $(P<0.05)$ between the two. The soil outside the poultry enclosures are probably contaminated by bird attendants who match on some droppings and carry such droppings on the soles of their shoes to the soil outside the enclosures. The organisms from broilers droppings are known to be resistant to antibiotics as a result of incorporation of antibiotics into the poultry feed formulations to aim at preventing infection. Therefore droppings carried by attendants to the soil outside the enclosure, must equally contain organisms resistant to antibiotics. This agrees with Smith (2005) who reported the incorporation of antibiotics such as bacitracin, tetracycline, oxy- and chloro-tetracycline into poultry feed, thus resulting in resistance.

Salmonella-like organisms have been recognized as the leading cause of bacterial food poisons. This has been attributed to their ubiquity in the natural environment (Beli et al., 2001). Beli et al., (2001) further states that the physiological adaptability of Salmonella to hostile conditions in the natural environment safeguards their survival and infectious potential. This explains why Salmonella-like isolates could thrive in soils outside the poultry house and continue to be resistant to antibiotics. As shown in this study, there is a significant increase in antibiotic and multidrug resistance in Salmonella-like species, compared to previous studies in other parts of Nigeria (Irajian et al., 2009). The study further revealed an association between multiple antibiotic resistance in bacterial pathogens which could be passed on to human through gene transfer, and that may be due to the use of antibiotics for non-medical purposes which help the increase of reservoir of $\mathrm{R}$ factor and multiple antibiotic resistances (Irajian et al., 2009).

Although Beta-lactamas activity has been found in other organisms like Staphylococcus aureus, Neisseria gonorrheae especially against penicillin and cephalosporins, etc (Cheesbrough, 1991), incidence of beta-lactamase activity has been reported among other bacteria. This study shows extended Beta-lactamase activity of Salmonella on Amoxicillin and Clavulanic $(\mathrm{R}=<$ $13 \mathrm{~mm})$, Cefotazime $(R=<14 \mathrm{~mm})$ and Ceftazidime $(R=<$ $14 \mathrm{~mm})$. Beta-lactamase activity among Salmonella-like isolates with Cefotazime showed the highest resistance, while Ceftazidime showed the least resistance by all the isolates. A similar activity has been reported among Salmonella species in other countries like Turkey, Nepal and South Africa (Irajian et al., 2009). The enzyme has been reported to bring about resistance to Cefotaxime, Ceftazidime and aztreonam as it is coded on conjugative plasmids, transposons or integrons, genetic materials which can be spread readily (Irajian et al., 2009).

\section{CONCLUSION}

It is concluded that there is a widespread Beta-lactamase activity in and around the poultry, causing antibiotic resistance of Salmonellae and other species of bacteria. This obvious resistance pattern observed could be due to Beta-lactamase activity which is a presently known problem of antibiotic resistance. This is a serious health implication for poultry consumption and therefore the need for the control of indiscriminate antibiotic use in poultry, a situation which encourages antibiotic resistance thus exacerbating an existing global problem of antibiotic resistance.

\section{REFERENCES}

AAM (1999). Antimicrobial Resistance: an ecological perspective, Report on a colloquim held on July 16 18, 1999 in Peurto Rico. American Academy of Microbiology

Arikpo, G. E., Eja, M. E., Ikpeme, E.M., Ofor, U. A., Enyi-Idoh, K. H. and Udosen, G. (2006). Antibiotic resistance patterns in a Calabar Poultry, Cross River State, Nigeria. Nigerian Journal of Microbiology 20(3), 1244-1251.

Bailey, N. T. J. (1981). Statistical methods in biology. $2^{\text {nd }}$ ed. London: Hodder and Stoughton 216pp.

Bauer, A. W., Kirby, W. M., Sherris, J. C. and Turck, M. (1966). Antibiotic susceptibility testing by a standardized single disk method. American Journal of Clinical Pathology 45, 493-496.

Carraminana, J. J., Rota, C., Agustin, I. and Herrera, A. (2004). High prevalence of multiple resistance to antibiotics in Salmonella serovars isolated from poultry slaughter house in Spain. Veterinary Microbiology 104, 133-139.

Cheesbrough, M. (1991). Medical laboratory manual for tropical countries. London: English Language Book. 
Cheesbrough, M. (2002). District Laboratory Practices in Tropical Countries. Part II, United Kingdom: Cambridge University Press, pp 182-187.

Irajian, G., Ranjbar, R. and Moghadas, A. J. (2009). Detection of Extended spectrum Beta-lactamase producing Salmonella spp and Multidrug Resistance Pattern. Iranian Journal of Pathology 4(3), 128:132.

Jorgensen, J. H. and Ferraro, M. J. (1998). Antimicrobial susceptibility testing: general principles and contemporary practices. Clinical Infectious Diseases 26, 973-980.

Livermore, D. M. and Brown, D. F. (2001). Detection of Beta-lactamases-medical resistance. Journal of Antimicrobial Chemotherapy 48, 59-64.

Miller, J. C. and Miller, J. N. (1986). Statistics for analytical chemistry. Chichester: Ellis Horwood 202 pp.

Molla, B., Mesfin, A. and Alemayehu, D. (2003). Multiple antimicrobial-resistant Salmonella serotypes isolated from carcass and giblets in Delre Zeit and Addis Ababa, Ethiopa. Ethiopian Journal of Health Development 17(2), 131-149.

Okeke, I. N., Laxminarayan, R., Bhutta, Z.A., Duse, A. G., Jenkins, P., O'Brien, T. F. and Pablos-Mendez, A. (2005). Antimicrobial resistance in developing countries. Part I: Recent trends and current status. Lancet Infectious Disease 5, 481-493.

Philips, I. (1991). A guide to sensitivity testing. Reports on the working party on antibiotic sensitivity testing of the British society for antimicrobial chemotherapy. Journal of Antimicrobial Chemotherapy 27, 1-50.

Philippon, A., Arlet, B. and Jacoby, G. A. (2002). Plasmid-determined Amp C-type $\beta$-lactamases. Antimicrobial Agents Chemotherapy 46, 1-11.

Pokharel, B. M., Koirala, J., Dahal, R. K., Mishra, S. K., Khadga, P. K. and Tuladher, N. R. (2006). Multidrug-resistant and extended-spectrum betalactamase (ESBL) - producing Salmonella enterica (serotypes Typhi and Paratyphi A) from blood isolates in Nepal: surveillance of resistance and a search for newer alternatives. International Journal of Infectious Disease 10, 434-438.

Smith, W. T. (2005). Feed Chickens Properly Cooperative Extension. Extension Service of Mississippi State University, pp. 58-60. 